\title{
Aligning BIM and Lean Methodologies within Capital Works Management Framework in Ireland
}

\author{
Barry McAuley \\ Technological University Dublin, barry.mcauley@tudublin.ie \\ Alan Hore \\ Technological University Dublin, alan.hore@tudublin.ie \\ Muiris O'Loingsigh \\ Technological University of Dublin, Muiris@OLoingsigh.com
}

See next page for additional authors

Follow this and additional works at: https://arrow.tudublin.ie/beschreccon

Part of the Construction Engineering and Management Commons

\section{Recommended Citation}

O'Loingsigh, M., Hore, A., McAuley, M. and Deeney, J. (2014)Aligning BIM and Lean Methodologies within Capital Works Management Framework in Ireland, Proceedings of the International Conference on Computing in Civil and Building Engineering, Orlando, Florida, June 23rd - 25th doi:10.21427/8mzz-z737

This Conference Paper is brought to you for free and open access by the School of Surveying and Construction Management at ARROW@TU Dublin. It has been accepted for inclusion in Conference papers by an authorized administrator of ARROW@TU Dublin. For more information, please contact arrow.admin@tudublin.ie, aisling.coyne@tudublin.ie,gerard.connolly@tudublin.ie. 


\section{Authors}

Barry McAuley, Alan Hore, Muiris O'Loingsigh, and John Deeney

This conference paper is available at ARROW@TU Dublin: https://arrow.tudublin.ie/beschreccon/61 


\title{
Aligning BIM and Lean Methodologies within Capital Works Management Framework in Ireland
}

\author{
Muiris O’Loingsigh ${ }^{1}$, Dr Alan Hore ${ }^{2}$, Barry McAuley ${ }^{3}$ and John Deeney ${ }^{4}$ \\ ${ }^{1,2,3 \& 4}$ School of Real Estate and Economics, Dublin Institute of Technology, Bolton \\ Street, Dublin 1, Ireland,
}

Muiris@ OLoingsigh.com; alan.hore@dit.ie; barrymcauley@gmail.com \& johnp1979@hotmail.com

\begin{abstract}
In 2007, following continued dissatisfaction with the lack of cost certainty on publicly funded projects, the Irish Government introduced the Capital Works Management Framework (CWMF). This framework had stated strategic objectives of achieving greater cost certainty at contract award stage; better value for money at all stages during project delivery and, more efficient end-user delivery. The framework, in particular, sought to rebalance risk, so that there was an optimal transfer of risk to the contracting authority and the contractor through the implementation of fixed price contracts. Coinciding with the introduction of the CWMF, there was significant debate around the introduction of Building Information Modelling (BIM) internationally, in assisting with the delivery of greater efficiency and, cost certainty of Public Works Contacts (PWCs). In this paper the authors' aim was to investigate how best to align the virtues of BIM methodologies with the stated aims of the CWMF. In particular, this paper will focus on the more appropriate transfer of risk to a contracting organisation operating within under PWCs where BIM is implemented.
\end{abstract}

\subsection{INTRODUCTION}

The Irish State in recent years, has suffered substantial cost over-runs in the public works sector, which has pushed the Irish government to explore new ways of controlling project costs. Traditional public forms of contract used, gave rise to major differences between tender prices and final project costs (Tobin, 2004). The continuation of poor cost certainty forced the Irish government to re-think its procurement strategy. This resulted in the introduction of the CWMF in 2007. As the framework was being implemented, Building Information Modelling (BIM) was gaining significant international interests. This was evident in the decision by the UK authorities to mandate the introduction of BIM by 2016. This plan was devised around a hypothesis which defined a scenario in which the Government client would have an estate that was smarter and better equipped to face a low carbon economy, with associated reductions in delivery and carbon emission (Government Construction Client Group, 2011). This paper investigates how the CWMF seeks to achieve its stated aims and, how BIM might be din the delivery pf public works projects in Ireland to assist in complimenting the CWMF stated aims. 
Recent reports commissioned by the Irish research agency Forfás put Lean construction and BIM at the forefront of transforming the Irish construction industry (Forfás Report, 2013). Despite the proximity of the UK BIM, progress is slow in Ireland in regard to BIM adoption by public works authorities (McAuley et al, 2012)

The authors' share the early experience of public work project teams in beginning their journey in the use of collaborative BIM technologies. While it will be seen that project teams found the use of these technologies very positive, their feedback reaffirms the need for more formal introduction of lean and BIM methodologies into the public procurement in Ireland.

\subsection{CAPITAL WORKS MANAGEMENT FRAMEWORK}

Since 2008, the Republic of Ireland has fallen victim to a serious economic downturn. An over-heated economy, driven by a construction and property boom, led to a collapse of the AEC sector (Cullinane and Dundon, 2011). In particular, the Irish public sector authorities experienced major differences between tender and final account completion costs. This eventually led to the introduction of the Capital Works Management Framework (CWMF) in 2007. The aim of the CWMF was to ensure that there was a reallocation of risk, to ensure greater certainly in respect to final outturn costs. The introduction of the new standard forms of contract soon became very contentious and quickly created an adversarial culture due to the perceived unfairness in the balancing of risk (Frasier, 2013). Since the introduction of the CWMF there has been consistent problems in the administration of these public works contracts, with a significant number of projects ending up in formal disputes ( Fogarty, 2007 and Edge, 2006)

\subsection{METHODOLOGY}

The authors collated different sources of primary data, in order to increase the validity of the research and investigate the appetite for more collaborative methodologies integrated into the CWMF. A number of data methodologies were adopted, in order to commencement engagement with the Irish AEC sector in regard lean and BIM methodologies. The authors report on two recent simulated pilot projects involving public work project teams, in order to gauge the level of use and capability of the Irish AEC sector to embrace BIM technologies on public works projects.

\subsection{RIAI/CITA CASE STUDY}

In an attempt to promote BIM within the Irish AEC / FM sector, a pilot project was launched in late 2012 by the Royal Institute of Architects in Ireland (RIAI) and the Construction Information Technology Alliance (CITA). This project involved a full professional team working in conjunction with the Department of Education and Science (DOES) on a generic primary school project. The main goals of the workshop included: 
- raising awareness and promotion of BIM;

- demonstrating a more effective way for teams to collaborate;

- assessing / demonstrating some of the BIM software tools available and

- validating designs through digital analysis.

A workshop was held over four days in the middle of 2012 with a number of subsequent presentations given to industry leaders. The workshop involved the deconstruction of an existing primary school building model and rebuilding it using BIM technologies (Figure 1). This involved a whole project team working in collaboration to maximise construction and sustainability potential, through the harnessing of BIM technologies.

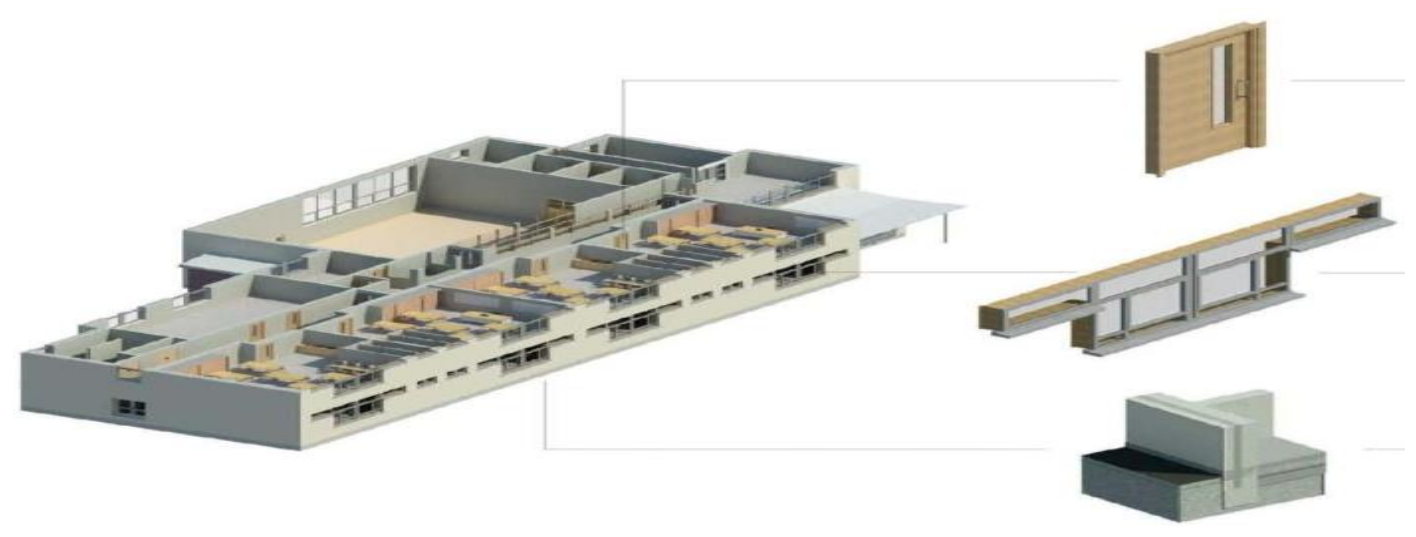

Figure 1: Deconstruction of School BIM Model

The pilot team consisted of a number of leading design professionals from selected firms within the Irish AEC/FM sector. This team also consisted of additional support from contractors, quantity surveyors, technical support, FM support for handover documentation and BIM energy specialists. Most significantly, there was observers from a number of the public sector agencies and government Departments, namely, Office of Public Works (OPW) and the Department of Education and Science (DoES).

The design team was provided with a digital brief with the overall goal to design a BIM model of a standard generic DOES school. This model was exploded into individual building components and then given to the design team to work on specific elements. The various professionals involved all worked on their own model, which was subsequently synchronized on a central server, allowing all participants of the workshop to monitor each other's work and, therefore, promote greater collaboration.

The results of the workshop strongly advocated the application of BIM to become mandatory in future public works projects. The BIM model helped to test eventualities that could potentially occur on site and subsequently aided in avoiding potential problems. The building was virtually built which allowed foresight on a number of key areas. The BIM process allowed for greater cost certainty and reduced a significant amount of the design risk. The collaborative process enabled the design 
team to see what the other disciplines where doing and fostered a greater team ethic throughout the design process. The design team were in a position to identify areas of possible clash detection and amend the design.

It was found through the analysis of the pilot and workshop, that BIM can address the following specific goals of the CWMF;

1. Greater cost certainty- BIM can provide a greater cost certainty at contract award stage, as the mass model studies allow design teams to design to a cost, rather than cost to design;

2. Award contracts on the basis of a lump-sum fixed-price - The BIM model provides exercises in design, programming, cost and value management and concept energy analysis. This allows a more accurate financial assessment for a contract with a fixed price.

3. Rebalance the risk - The risk factor can be better predicted through having a virtual model which enables clash detection and avoidance of a number of eventualities.

4. Value for Money - BIM enables a whole life cycle approach, through its unique access to a combination of energy analysis tools that complement the BIM process. This approach offers a much greater value for money to the client as it addresses their needs over the structures life.

5. Efficient delivery of the projects - BIM enables testing of design solutions to provide a more responsive building design to the client brief, and, better coordination of all project information.

\subsection{CITA BIM PILOT}

In late 2012, a small group of enthusiastic professionals active within the CITA, agreed to approach a public sector client about the use of an existing community centre building, as a vehicle for a CITA BIM pilot project. Throughout 2013 , the pilot team presented monthly progress reports to industry on the maturity of the BIM.

The original framework for the Pilot Project resulted in a development map that produced a number of interesting areas in which the topographical areas where complicated, resulting in it being too difficult to design on a 2D campus. This resulted in an enhanced brief being suggested to the Client for the creation of a virtual model for the whole area which could be further used to analyse and investigate best design options. This model further presented an interesting building in the form of Rowlestown community centre. The community centre was in need of some form of refurbishment and offered the chance for the CITA Pilot Team to create a sustainable and functional building (Figure 2). This brief involved two phases of the project with phase one ultimately aiming to revaluate the current structure and produce a solution for a more functional building. This has been based around the Clients needs, which includes better thermal comfort, enhanced artificial lighting, improved acoustics, upgrade to the Crèche, as well as the addition of a shop unit. 
A specialist scanning company where asked to provide survey data for the project. They combined three methods to achieve this, by firstly setting up a GPS grid of the area, secondly a UAV was flown over the area capturing digital information. The UAV was pre-programmed using Google earth and GPS, flew over the area capturing pictures which could be used to create a digital model of the area over a four hour period. Thirdly as there was no drawings were available, a laser scan of the building was completed (Figure 3).

Before commencement of the scheme design could begin, there were a number of different BIM standards investigated. The AEC (UK) BIM Standard was selected. The pilot project represented the opportunity to demonstrate how these standards would be implemented from the very beginning (BS 1192 - stages overview).
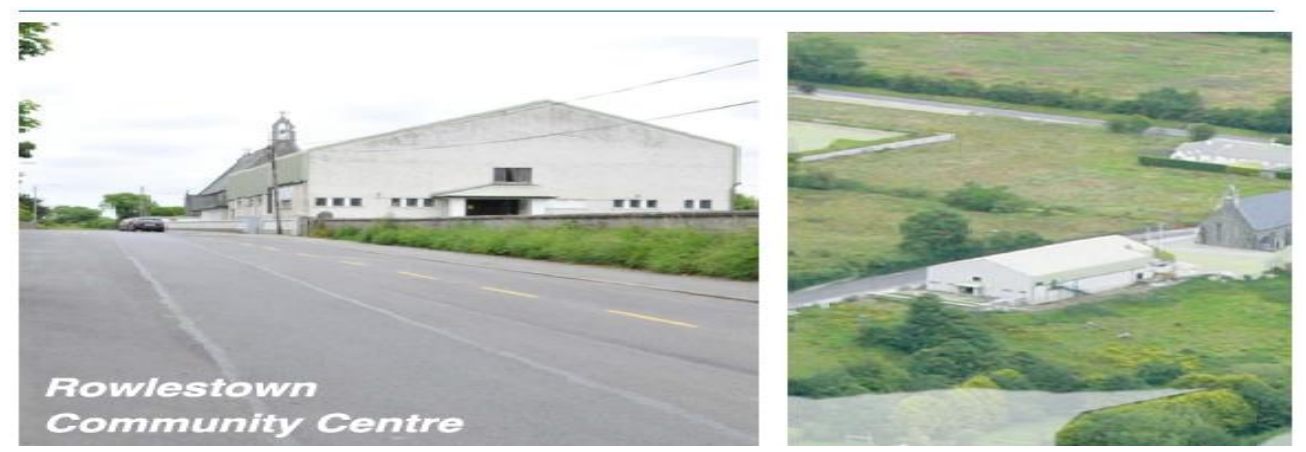

\section{Figure 2. View of Existing Building}

Before commencement of the scheme design could begin, there where a number of different BIM standards investigated. The AEC (UK) BIM Standard was selected. The pilot project represented the opportunity to demonstrate how these standards would be implemented from the very beginning (BS 1192 - stages overview).

The 3D terrain model that was received from specialist scanning company was then imported into Archicad and then further taken through Google SketchUp. A simplified model $(300 \mathrm{Mb})$ was used with a 20 million point cloud and a setting filter distance, which took an hour and a half to import, this represented a simplified $3 \mathrm{~d}$ model picture (Figure 3).

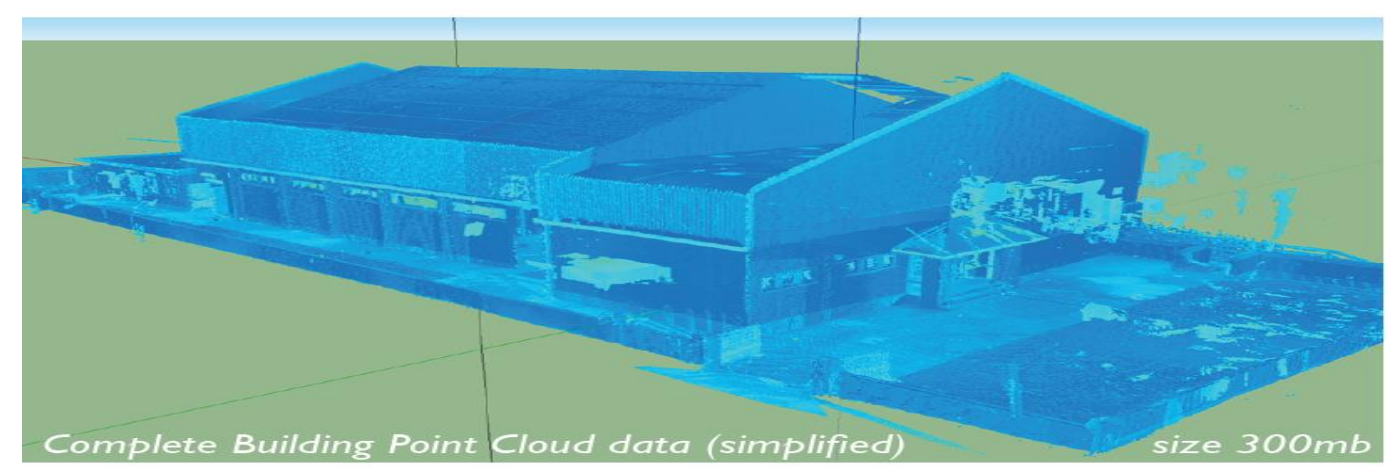

Figure 3. Complete Building Point Cloud Data (Simplified) 
Through combined point cloud data and the terrain data an existing building model was then constructed (Figure 4). As textures where applied to the model it became more realistic and gave a good platform to make decisions in which plans, sections and elevations could be easily generated (Figure 5).

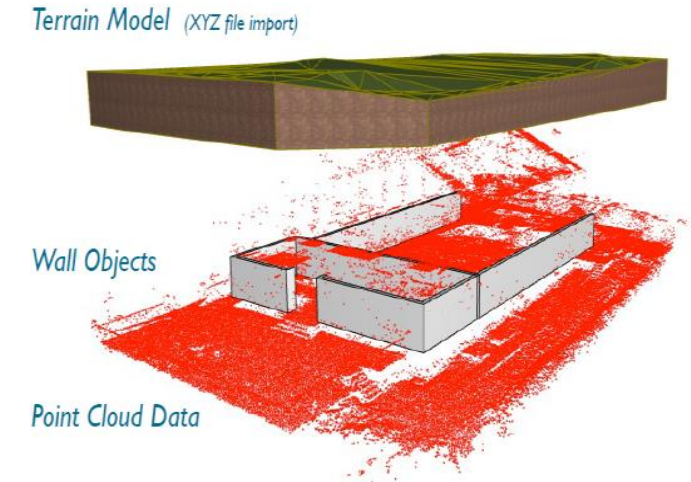

Figure 4. Merging of existing data

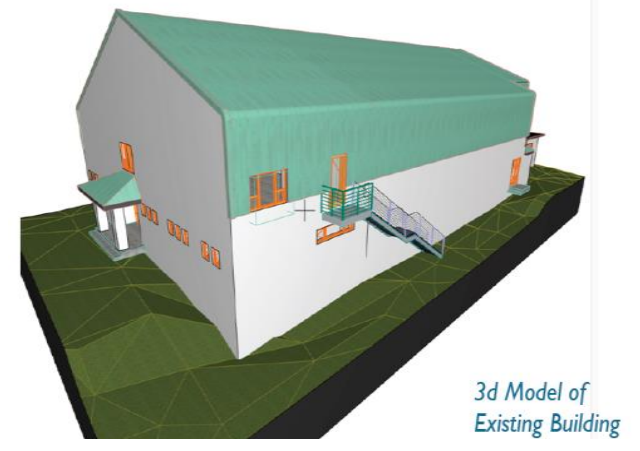

Figure 5. Existing Building Model

What followed was a complete design of the architectural, structural and building service elements. In additional cost consultants carried out a full 5D costing exercise and construction managers completed a 4D planning and scheduling exercise.



\section{Figure 6. Completed BIM model}

Through the integration of the team and using smarter workflows and technologies to facilitate more collaborative practice, resulted in better value for all involved, particularly the client and facility operation. This pilot offered a unique opportunity for the public sector client to see first-hand how through the use of a variety of 'BIM' 
authoring and interface tools could streamline the efficiency of the process. This further permitted the deliberate shifting of project focus from design and construction to FM and operation. The pilot project has indicated that through involvement of early FM at the design stage there is a good chance they it can have a high influence in affecting the project. This can ensure that the most functional and practical structure can be realised. This approach is of high importance due to the OPW recently announcing its Property Asset Management Plan (PAMP) in which it is hoped that effective property asset management will be key to reducing costs on public service delivery. The pilot results have shown that BIM can be an enabler in further advancing the suggested web-mapping register to be installed by the OPW which will show core data for all State buildings and lands.

The pilot also demonstrated in a number of instances where particular focus could be given to the removal of waste and more attention on adding value for the Client. An example of this within the pilot was through the survey data which showed a large drop resulting in the only place to position the on-site compound being beside this. This allows the contractor from the offset to see where a number of possible problem areas may occur. It also allows for a number of construction methodologies to be examined and further savings for the client. The building's interior was also modelled in which permitted an informed design to be undertaken so the client and planning authorities could easily understand the design intent within the location.

\subsection{CONCLUSION}

The CWMF provides a comprehensive set of procedures for effective cost certainty. Without changing the fundamental principles of the framework and, working within the reporting and contracts restraints, BIM can further improve value and risk management while improving final output. There is however, need for further research into how BIM methodologies can be better aligned to satisfy public sector requirements as detailed in the framework.

The government's promised review should be supported by research into the CWMF performance focusing on the levels of cost and programme over runs, analysis of risks encountered and realised, impact of mandated improvements in contractors value and risk management, extent to which contract terms have been enforced and, levels of disputes and their primary causes.

The government's review must also address the key concerns raised by the industry such as risk allocation, failure to provide completed design before risk transfer, fairer and more sustainable risk management burden, and removal of adversarial approach to construction contracts. Further to this there must be particular attention given to how the government plan to operate and maintain these procured assets, as there has been no evidence to date to suggest the CWMF offers the client or public value for money. The review of the CWMF has lead the author's to conclude, that all parties to contract, including the client, must continue to manage and, where possible reduce risk, rather than simply delegating it. 


\section{REFERENCES}

Cullinane, N. and Dundon, T. (2011) Redundancy and workplace occupation: the case of the Republic of Ireland, Employee Relations, Vol. 33, No. 6, pp. 624-641.

Department of Finance (2007) Capital Works Management Framework - Guidance Note for Public Works Contracts, Department of Finance

Edge, Derrick, (2006) Annual Dinner-President Speech, Association of Consulting Engineers of Ireland, Available at<www.acei.ie/2006_presidents_speech.asp (accessed 08/11/11)

Fogarty, Dan. (2009) Contractor perspective of the new Irish Public Works Projects, Management Procurement and Law, Proceedings of the Institution of Civil Engineers, Feb 09, pp 29-34

Forfas Report (2013) Ireland's Construction Sector: Outlook and Strategic Plan to 2015, available at

Tobin, M. (2004), Statement by Mr Michael Tobin, Chief Executive NRA, to the Committee of Public Accounts on 15th July, 2004, available at < http://www.nra.ie/News/PressReleases/2004/htmltext,2467,en.html>accessed $(27 / 03 / 2012)$

Fraser, S. (2013) The adoption of BIM within the Public Works Contracts (PWC) suite of construction contracts in Ireland, Proceedings of the CITA BIM Gathering, November 14th -15th, pp 159-162

Government Construction Client Group (GCCG) (2011) A report for the GCCG BIM Working Party Strategy Paper - Mar 11, UK Government

McAuley, B., Hore, A.V and West, R. (2012) Implementing of Building Information Modelling in Public Works Projects in Ireland, Proceedings of the 9th European Conference on Product and Process Modelling, Reykjavik, July 25 - 27th 2012,pp $589-596$

Office of Public Works (OPW) Property Asset Management Delivery Plan, Office Public Works.

Tobin, M (2004) Statement by Mr Michael Tobin, Chief Executive NRA, to the Committee of Public Accounts on 15th July, 2004, available at < http://www.nra.ie/News/PressReleases/2004/htmltext,2467,en.html>accessed $(27 / 03 / 2012)$ 